\title{
IMPROVING ACQUISITION OF LEARNING THROUGH PEER-MEDIATED SUPPORT STRATEGIES IN TEACHING RESEARCH
}

\author{
Joseline M. Santos, Ph.D \\ College of Education, Bulacan State University \\ City of Malolos, \\ Bulacan, Philippines
}

Article DOI: https://doi.org/10.36713/epra4496

\begin{abstract}
The conduct of an action research enabled teachers to assess the research capabilities of the students specifically in writing the different parts of the paper. The aim of the study is to improve the learning acquisition of students through peer-mediated support strategies in teaching research. The participants of this study were the Senior High School students taking Research Project as a subject. A pre-writing activity was administered to identify the needs of the students in writing the different parts of the research. A learning plan integrating the use of the Peer-mediated Support Strategies (PMSS) such as classroom-wide peer tutoring, peer support arrangement and lunch bunches as interventions, was developed to improve the performance of the students-participants in writing research. A post-writing activity was given as well to the participants to find out if there were significant improvements in their writing capability. The study used methodological triangulation. Descriptive and inferential statistics were used to analyse and compare the results of the pre-writing and post-writing scores. A focus group discussion and teachers' observation were conducted to support the result of the analysis made. The result was found to be significant proving PMSS to be an effective strategy in improving acquisition of learning.
\end{abstract}

KEYWORDS: Research writing, acquisition of learning, peer-mediated support strategies, peer assisted learning, classroom-wide tutoring, peer-support arrangement, lunch bunches

\section{INTRODUCTION}

Learning is important because no one is born with the ability to function competently as an adult in society (National Academy of Sciences, 2019), but guiding students to learn how to learn is more important for them to process the information they acquire. Not all students have the same level and way of acquiring knowledge, even if they are in the same classroom having the same teacher. Students in the classroom are greatly varied, both in terms of capability and characteristics. The teacher's persistence is necessary in embracing all students, so that the instruction becomes effective and succeeds in optimizing the capability of the students. (Hapsari, Darhim \& Dahlan, 2018). Students' level of understanding differ based on their capability and capacity to learn. Learning is enhanced when it is more like a team effort than a solo race. Good learning, like good work, is collaborative and social, not competitive and isolated. Working with others often increases involvement in learning. Sharing one's own ideas and responding to others' reactions improves thinking and deepens understanding (CRLT, 2016). The aim of the study to improve the learning acquisition of students through peer-mediated support strategies in teaching research. The study used a mixed method approach to measure the writing capability of the students, observation from experts and focus group discussion among peer tutors and peer learners.

Many students are being left behind by an educational system that some people believe is in crisis. Improving educational outcomes will require efforts on many fronts, this can be improved by helping students to better regulate their learning through the use of 
effective learning techniques (Dunlosky et al, 2013). Teachers keep on researching and undergoing trial and error on how students will improve their performance in the classroom. One of the strategies being tested peer-mediated support strategies (PMSS) which involves one or more peers providing assistance to their classmates (Bell and Carter 2013). Other names of these strategies are peer-assisted learning (PAL), peersupport strategy, peer tutoring and peer learning. Peerassisted learning which has been described as "the development of knowledge and skill through active help and support among status equals or matched companions" (Carr et al, 2016). Peer learning is not new and neither is the emphasis on collaboration as cited by Bone (2015). This strategy enables teachers to address individual student needs, as well as observe students and develop individual remedial lessons (Blueprints for Healthy Youth Development, 2019).

PMSS has been proven effective in different areas of learning. Regelski (2016) reported PMSS as effective strategy and recommended that teachers can add PMSS as an effective program to improve reading comprehension and reading fluency skills for students with Autism Spectrum Disorder (ASD). In the study of Han, et. al. (2015), they used peer-mediated support strategy to encourage students to participate more actively in the dissection process and promotes thoughtful dissection. The result of the study shows self-assessment scores regarding the learning objectives related to upper limbs were significantly higher in experimental group than in control group. Additionally, experimental group received significantly higher academic scores than did control group. The students in peer-mediated learning perceived themselves as having a better understanding of course content and achieved better academic results compared with those who participated in faculty-led dissection. Peer-mediated dissection contributed to self-perception and to the ability to retain and explain anatomical knowledge.

Reinholz (2015) in his study, advances a model describing how peer assessment supports selfassessment. The model, assessment cycle, draws from theories of self-assessment to elaborate how learning takes place through peer assessment. The actual learning benefits were consistent with what the assessment cycle would predict; the more the activity structure supported goal awareness, performance awareness and gap closure, the more that students learned. However, in the study conducted by the Institute of Education Sciences (IES) of US Department of Education (2013) revealed a little evidence on the effect of PMSS. The review of Adolescent Literacy interventions addresses student outcomes in four domains: alphabetic, reading fluency, comprehension, and general literacy achievement. Based on this study, the IES considers the extent of evidence for Peer-Mediated Support Strategies on adolescent learners to be small for the comprehension domain. The effect was not statistically significant (when adjusted for clustering), but it was large enough to be considered substantively important (i.e., an effect size of at least 0.25). Thus, for the comprehension domain, one study showed substantively important positive effects. This results in a rating of potentially positive effects, with a small extent of evidence.

PMSS is assumed to be effective in improving learning acquisition of students in teaching research. A lot of studies were conducted proving its effectiveness in different areas of learning like reading comprehension, mathematics and sciences. However, there were no studies existing that used peer learning in teaching research. The procedure of the conduct of PMSS in this study was another approach on how the strategies implemented in the class. The aim of the study to improve the learning acquisition of students through peer-mediated support strategies in teaching research. Research as a subject is challenging, not only to the students but also to the teachers. Teachers teach to impart their knowledge and skill to the students. Students go to school to acquire learning, make meaning and apply to the real-world scenarios. The call of teaching is not simply sharing what the teacher's know and what the teacher can do, but, together with these are the use of effective strategies and approaches that will help the students at the end. Contributing another approach to the three stages of PMSS and proving its effectiveness in teaching research were the main reasons why the researcher would like to pursue this study.

\section{Statement of the Problem}

The role of the teacher is an important factor in helping the development of learning, but as what recent studies have proven like in the studies of Regelski, Han et.al, and Reinholz, peer is also an important factor in the learning process. In Bulacan State University-Laboratory High School, writing a research paper is usually done by group because of the number of students in each class. Doing individual research is a heavy paper work for both the teacher and the students. But since not all members of a group research have the same capability in writing, other members are merely passive participants that never had quality contribution in writing the paper. This is the very reason why the research was conducted. The study assessed the capability of individual students in writing research and identified those who are in need of assistance (peer learner) and those who can help (peer 
tutor). It was assumed that peer-mediated support strategies (PMSS) will help the peer learner to improve the acquisition of learning in writing research with the help of the peer tutors.

The researcher sought answers to the following questions:

1. How can PMSS be effectively implemented?

2. What is the writing capability of students in writing research before and after the implementation of PMSS?

3. What are the significant learning derived by the teachers as observers and students as peer learners and tutors on the process and outcome of the use of PMSS in writing research?

\section{MATERIALS AND METHOD Research Design}

The study utilized a mix method approach which used methodological triangulation. Methodological triangulation involves using more than one kind of method to study a phenomenon (Bekhet A. \& Zauszniewski, J., 2012). A pre-writing activity was administered to identify the needs of the students in writing of the parts of research. A learning plan integrating the use of Peer-mediated Support Strategies (PMSS) such as classroom- wide peer tutoring, peer support arrangement and lunch bunches as interventions were developed to improve the performance of the students-participants in writing research. A post-writing activity was given to the participants to find out if there were improvements in their writing capability. Descriptive and inferential statistics were used to analyse the result of pre-writing and post-writing scores. A focus group discussion and teachers' observations were conducted to support the result of the analysis made.

\section{Participants}

This study involved 192 Senior High School graduating students of Bulacan State UniversityLaboratory High School for the School Year 20182019 which consist of four sections under the strands of Accountancy, Business and Management (ABM), Humanities and Social Sciences (HumSS) and Science, Technology, Engineering and Mathematics (STEM), who were involved in both the pre-writing and post- writing activities. They were considered the subjects of the study. There are 125 students who are involved in writing the introduction part of the research and there are 167 students who participated in writing the part of the methodology. Unequal number of participants was caused by the inconsistent number of attendance during the conduct of the research. Among these students, 31 took part as peer tutors and the remaining as peer learners.

\section{Measures}

The research write-ups of the students were checked using a rubric for research reported in traditional format adopted from Wesley College Department of Education. This rubric is used for formal knowledge production products that require a traditional research reporting format: action research, literary research, scientific research, social science research, or historical research. (Wesley College, 2009). This rubric was used in checking the Introduction and Methodology part of the research because these are the only parts that time permits to do individually.

The PMSS implementation was observed by the teachers and the guide questions using formative observation of teaching: focusing peer assistance on teachers' developmental goals (Drew et al, 2016). The researcher adopted the questions related to gaining feedback on the conduct of PMSS.

Group of students as peer tutors and peer learners were asked for feedback on the process of PMSS. Questions for Focus Group Discussion (FGD) were adopted from the research article "Helping each other to learn - a process evaluation of peer assisted learning" (Glynn et al, 2006).

\section{RESULTS AND DISCUSSION Implementation of PMSS in Improving Acquisition of Learning in Writing Research}

Peer learning needs a formalized, systematic approach so that students can learn how to learn - this is not something that necessarily comes innately as different pupils learn in different ways (Vaks, 2018). The three approaches of PMSS were not implemented separately but a series of approach wherein one is the continuation of the other. 


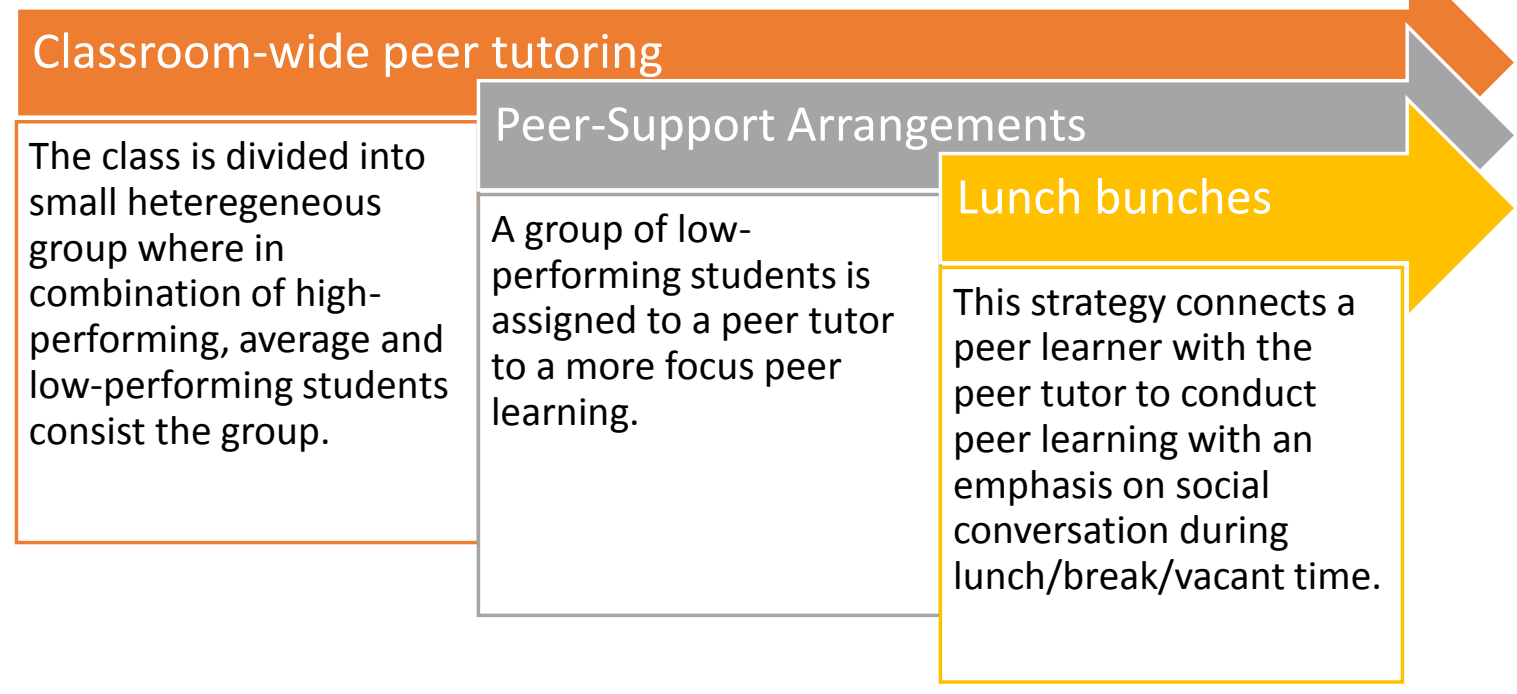

Figure 1. Systematic approach to PMSS

PMSS is a strategy to develop knowledge and skill through active help and support among status equals or matched companions" (Carr et al, 2016). Peer learning support formally involves peers (other students) in the delivery of support (Koch, 2017). PMSS was used in this study in three phases: (1) Classroom-wide peer tutoring. It is a peer learning strategy that divides the classroom into small, heterogeneous learning groups. Teams consist of at least one high-performing student, average students and low performing students. (2) Peer-Support Arrangements. It involves equipping one or more low performing students in an inclusive group to provide academic support. (3) Lunch bunches. This strategy "lunch bunch" connects a peer learner with the peer tutor to conduct peer learning with an emphasis on social conversation during lunch time. The processes made in this study can be compared to the writing fellows inspired by Brown's or Carleton's models. Writing fellows are writing tutors who are attached to or embedded in a specific course and provide feedback on student drafts to emphasize the process of conversation, drafting, feedback, and revision (Koch, 2017).

\section{Steps to Implementation}

The process of implementation of PMSS in this study was anchored from study of Bell and Carter (2013). Four steps were implemented to make the implementation of PMSS possible. It consists of Planning Supports in Context (Step 1) considering the content, assessment, expectations, opportunities, social and behavioral skills, setting and interaction initiated; Selecting Peers (Step 2) followed next as good social and interpersonal skills, shared interests with focal student, consistent attendance, and a history of being reliable and responsible the qualities of peer tutors; Orientation on the conduct of the process (Step 3) on the next stage; and Monitoring and Providing Feedback to Peers (Step 4) tackles on how to exit the process and giving feedback to the learners. 


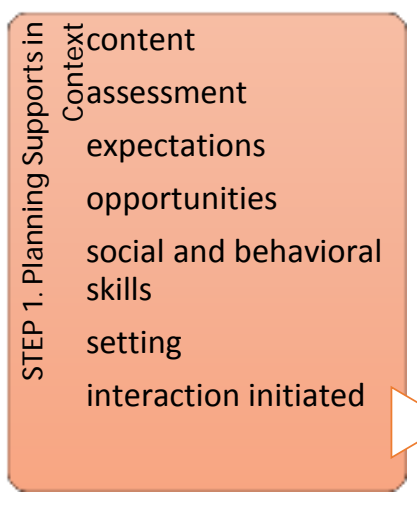

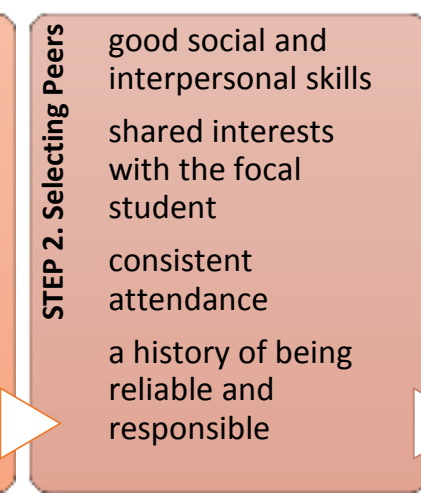
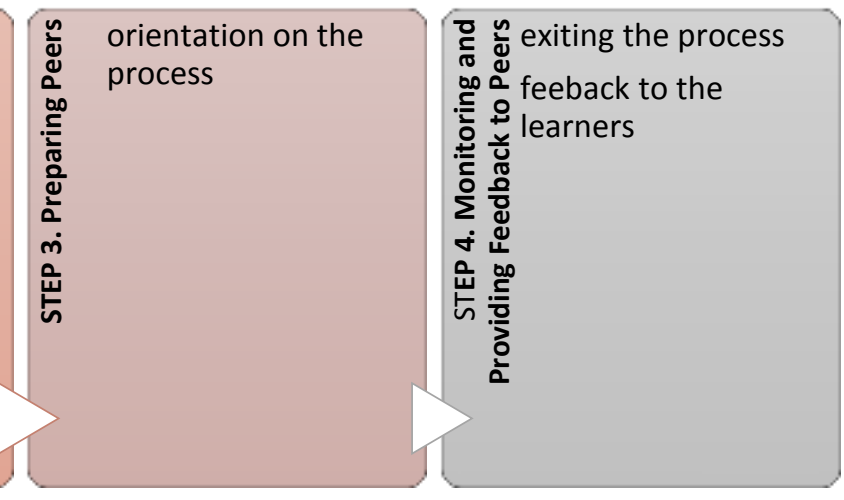

Figure 2. Steps to Implementation

\section{a. Introduction as Initial and Critical Part of the Paper}

A learning plan was developed to make the sessions structured. Organized peer tutoring can give greater results compared to unorganized peer tutoring (Ali and Anwer, 2015). After the discussion based on the learning plan of the lecture and activities, students were given assignment to write the introduction. After checking, the teacher identified the peer tutors and peer learners. Peer tutors are usually the leaders of the group last semester and they got perfect score. Peer learners were categorized in to two, average and lowperforming. Average students are those who commit 35 mistakes in the assignment; low-performing students are those who got more than 6 or more mistakes.

The first phase of the implementation of PMSS is the classroom-wide peer tutoring. All identified peer tutors were assigned to group with students who are combination of average and lowperforming students. Peer tutors were given beforehand an orientation on the process of peer learning. The training of tutors plays an important role in the productivity of peer tutoring (Ali \& Anwer, 2015). The peer tutors studied the comment of the teacher to the papers and then started discussing in general the comment in their papers. Peer learners started to rewrite their introduction and ask questions to the peer tutors if they need clarifications. Papers were submitted to the leaders for checking and to the teacher for scoring. Average students improved their work in the first phase of PMSS. Peer instruction has been recognized as an instructional method having a positive impact on learning compared to traditional lectures (Moris et al, 2015). As what the peer learners mentioned in the interview that having the session gave them a chance to be better.

The second phase of the implementation of PMSS is peer-support arrangements. This phase happened because there are some peer learners who did not improve their work after the classroom-wide peer tutoring. Most of the average students improved their work but the low-performing were not. This is similar to the interpretation of Kodabux and Hoolash (2015) saying that the lecturer expects his students to develop a finesse in their academic writing and language. The cohort's large size often makes it impractical for one single lecturer to cater for the varying learning needs of all students within one-hour workshops. It is possible that there are some students who were not given enough focus by the peer tutor since there are 4-5 members in a group during the first session. It is also possible that the peer learners still need more guidance to acquire learning in writing the introduction. For the second time, peer tutors and peer learners discuss again but in a smaller group. Discussion between the peer tutors and peer learners did not end in the school. Peer learners take advantage of technology to make another platform and extend their conversation with the peer tutors. They communicate online using Facebook Messenger and chat with their peer tutors to clarify their thinking and writings and ask to check on the progress of their work.

After the session, for the third time, peer learners revised again their introduction. Papers were checked by the peer tutor and submitted to the teacher for scoring. Most of the papers got high scores but there are three more students who need focus.

The third phase of PMSS is "lunch bunch". This time peer learning is done one on one and not scheduled in the classroom but during their break time. These peer learners might be needing another strategy to get across to what they supposed to do. Despite these positive benefits, there also have been reports of negative outcomes, students not feeling safe or compatible with each other (Cited by Stenberg et al, 2019) that are seen to have an impact on student 
learning. This is one of the factors that needs to be considered in pairing peer tutors and learners. Peer tutor who stayed up to the end of peer learning can be considered as 'perfect mentors' as how Arrand (2014) who have time and patience to work one-to-one until the mentee has mastered the skill being taught. These peer tutors have seen dedication and initiative to help the peer learners who need extra focus in writing. The papers of the peer learners improved little by little and were able to submit for grading and recording.

PMSS role in the acquisition of learning is very observable. There are some students who really appreciate the sessions because they know they benefitted from it. This activity was substantiated by the information gathered from a focus group discussion (FGD) of peer tutors and peer learners.

\section{b. Designing paper through writing research methodology}

Another session was done to write the Research Methodology of the study. In the first meeting of the week, the different parts of methodology were explained comprehensively. An example paper was shown to the students for analysis of the different parts. The students wrote their methodology (research design, population and sample and hypothesis/assumption) individually. After a week, the methodology that was written individually was distributed. As expected most of the individual papers failed to get perfect scores of 15 points since it was done individually.

This time, peer-support arrangement was utilized. The students were then grouped by company which is their current grouping for the second semester anchored to their work immersion. Each group was asked to compare and analyse their answers individually to come up with the final methodology. The group wrote only one paper of methodology to correct their own perception on how the process of their research will be conducted. After the peer learning, the group came up with an improved Research Methodology. Papers were submitted to the teacher for checking and were checked by group and seen to be effective since $94 \%$ of the students got ten and above scores out of 15 items.

Writing capability of students in writing research before and after the implementation of PMSS

\section{a. Writing Introduction}

Table 1. Descriptive Statistics of Samples

\begin{tabular}{|l|l|c|c|c|c|}
\hline \multicolumn{2}{|c|}{} & Mean & N & Std. Deviation & Std. Error Mean \\
\hline \multirow{2}{*}{ Pair 1 } & Initial_Activity & 9.62 & 125 & 3.80 & .340 \\
\cline { 2 - 6 } & Final_Writing & 13.71 & 125 & 2.12 & .19 \\
\hline
\end{tabular}

Table 2. Paired Samples Test

\begin{tabular}{|l|c|c|c|c|}
\hline Activities & Mean & SD & t & $\begin{array}{c}\text { Sig. } \\
\text { (2-tailed) }\end{array}$ \\
\hline $\begin{array}{l}\text { Initial Writing Activity } \\
\text { Final Writing Activity }\end{array}$ & -4.09 & 3.51 & -13.03 & .00 \\
\hline
\end{tabular}

Tables 1 and 2 summarize the initial and final performance of the students in writing the introduction part of the research paper in IMRAD format. The total score for this activity is 15 points and 9 is set by the teacher as the passing score which is $60 \%$ of the total score. Mean score in the initial activity is 9.62 (Table 1) with a standard deviation of 3.80 (Table 1). Individual scores were examined and revealed that $39 \%$ of the students in the initial activity got lower scores than the passing score of 9 points. The final writing activity got a mean of 13.71 (Table 1) and a standard deviation of 2.12 (Table 1). The scores of the students improved and though students did not get perfect scores, the improvement from the initial activity is proven to be significant.
Subjecting the scores to a paired sample t-test, the value of $t$ is 13.03 (Table 2). Since the value of the probability is .00 , the result is significant. This means that the significant change in the scores between the initial activity and final writing of paper makes the use of PMSS as intervention in improving learning acquisition of students effective.

It clearly shows that acquisition of learning of the students in a new lesson varies in different level. The class listen to the lecture on how they are going to write the different parts of introduction. Activities were given to ensure that they make meaning on the learning they acquired, but based on the scores of the students in the first phase of writing activity, still many of them did not get perfect scores. A great deal of learning theory has been about how learning content is acquired 
(Illeris, 2018). Learning content falls on content dimension that consists of knowledge, understanding and skills. This is an existing problem when students used to be in group in their previous researches. Most of them just rely on the capability of the leaders to write, and these leaders share their agony on having a member who were not trained to write research. This is one of the problems addressed in this study, to identify the students who are experiencing problems in acquisition of learning content and those who are capable in writing research so that action can be done.
But, in the implementation PMSS in research writing, the result of the peer learning sessions helps a lot in improving their scores. Crawford and Cannon (2018) mentioned that after years of experience, they recommend the use of peer leaders to improve learning for their novice nursing students as it has been a successful strategy in their program. Findings from the 13 studies revealed mostly moderate to high effects favouring peer mediation, particularly when implementing a peer-mediated feedback component (Wexler et al, 2013).

\section{b. Writing Methodology}

Table 3. Descriptive Statistics of Samples

\begin{tabular}{|c|l|c|c|c|c|}
\hline \multicolumn{2}{|c|}{} & Mean & N & Std. Deviation & $\begin{array}{c}\text { Std. Error } \\
\text { Mean }\end{array}$ \\
\hline \multirow{2}{*}{ Pair 1 } & Individual & 12.38 & 167 & 2.99 & .23 \\
\cline { 2 - 6 } & By Group & 12.53 & 167 & 2.74 & .21 \\
\hline
\end{tabular}

Table 4. Paired Samples Test

\begin{tabular}{|l|c|c|c|c|}
\hline Activities & Mean & SD & t & $\begin{array}{c}\text { Sig. } \\
\text { (2-tailed) }\end{array}$ \\
\hline $\begin{array}{l}\text { Individual } \\
\text { By Group }\end{array}$ & -.15 & 3.24 & -.60 & .55 \\
\hline
\end{tabular}

Improvement in writing the methodology was found to be not significant. The value of $t$ is -0.60 (Table 4) while the value of the probability is 0.55 (Table 4). The result is not significant at $\mathrm{p}<0.05$. Students from the individual activity to final phase of writing already got high scores having the means of 12.38 (Table 3) and 12.53 (Table 3) with standard deviations of 2.99 (Table 3) and 2.74 (Table 3). This clearly shows that activities in the writing introduction made them familiar with their study and easily comprehend how they will work on the research methodology. Topping, et. al., (2017) suggest to incorporate continuous supervision and support for the students throughout the program, since only relying on an introductory training is unlikely to be sufficient. Peer learning does not end in the first phase of the implementation, since the groupings of the students are by company, they had conversation on how they are going to do their research when they are having work immersion. This support aims at further optimizing all important and trained aspects of both the cooperative and content-related interaction during peer learning and consequently leads to improved future collaboration. Take into account that this support can take the form of providing students with scripts and scaffolds for effective peer interaction (e.g., in view of fostering the peer dialogue, the processing of information, joint construction of knowledge, and problem solving) (Topping et al, 2017). Participants of this study are not new to research, in their curriculum this is already their third subject. However, their experience from previous semesters in doing research is by group and not individual that made them difficult to get high scores in individual activity at the start.

Significant learning derived by the teachers as observers and students as peer learners and tutors on the process and outcome of the use of PMSS in writing research

\section{a. Focus Group Discussions (FGD)}

Peer tutors and the peer learners experiences and insights on the conduct of PMSS were heard and noted through a focus group discussions (FGD). Each section were represented by one tutor and learner. FGD was done separately per section, separating the interview between peer tutors and peer learners. Questions are grouped into three sections which are Section 1. Settling In, Section II. Knowledge of, and attitudes to peer learning, Section 3. Expectations of the peer learning session.

The peer tutors and learners find many advantages on the conduct of PMSS. They find it a chance to be better and not immediately evaluated. Peer tutors feel that they are more confident because of the 
process; they feel their important role on the improvement of the writings of their peer learners. Peer tutors and learners hope someday that they will be more independent and gain more learning on writing research so that when time will come that they have to do another study, they are more ready and as peer learners, they hope to be the peer tutors who will guide their group members in the future.

\section{b. Teachers' Observation}

Three videos of peer-support arrangement strategy were observed by three experts in the field of education. The video shows how peer tutor handled the second phase of peer learning. The second phase of PMSS wherein a smaller number of peer learner/s who failed to improve their work in the first phase is/are assigned to each tutor.

In observing the session, the observers focus on clear learning aims and outcomes, scaffolding and testing understanding, and active learning and interaction.

These observations clearly show the differences and personality of peer tutors and peer learners that affect the process of peer learning. Peer tutors vary in their communication skills as observed in the video. Peer learning is a highly effective strategy for the students to learn from each other. It does not only benefit the students in academics but also help the students in developing their communication and interpersonal skills (Ali et al, 2015). Rahmasari (2017) states that peer tutoring is a very good way to get students involved in learning so that they are not just passive learners receiving information. Students do not always know how to manage the complex interpersonal scenarios involved in peer tutoring. So students might take a controlling approach to their peer learners (do as I say...) or lie to cover up a lack of knowledge. (Arrand, 2014). The process involves a lot of improvement but the initial process already benefited the students. Continued use of PMSS will refine the process and help more students to improve their acquisition of learning.

\section{CONCLUSION}

It has been mentioned previously on this paper that PMSS is not a new strategy and that many other fields of studies made use of it already. The researcher, in search for an effective strategy, was able to prove that PMSS, based on the result of this study, can be used as an effective tool to ensure effective teaching and learning in the subject Research.

As a process, it was found to be complex especially for first implementer. It was also noted that the various stages of PMSS require careful and strategic implementation to ensure positive results and to guarantee that no learner is to be left behind. The tutors played a very important role and contributed significantly on the overall impact of the strategy. The researcher observed that when the students are involved in their learning, they take ownership of it, and eventually become independent learners.

It is also worth mentioning that the use of technology in the form of Facebook Messenger contributed considerably in the process. Students find it difficult at times to inquire their doubts and confusions on anything about the lesson because they are afraid that their teacher might get annoyed at them. They find it easier to ask questions and clarify things with their peers because they believe that they can relate to them better and that they can explain things to them on their own level or cognition. Also, their peers can easily be available at any point of time because they can just send them a message in FB Messenger about their inquiry.

Research is not an easy subject. It requires initiative, a lot of motivation, and enough time to finish. Do not forget that it is not the only subject being taken by the students in the semester. Therefore, it is highly recommended for teachers to sit together, plan and map their curriculum so that the projects or culminating tasks/activities can be integrated to articulate both horizontally and vertically. The use of the PMSS can run across all subjects. The role of the tutors can be extended to all the subjects. A mentoring project can be linked to this as well. To ensure the applicability of PMSS to the other subjects, it is therefore recommended for the other teachers to conduct a similar study.

\section{REFERENCES}

1. Ali, N., Anwer, M., \& Abbas, J. (2015). Impact of Peer Tutoring on Learning of Students. Journal for Studies in Management and Planning, 1(2), 61-65. Retrieved

from https://www.researchgate.net/publication/31929223 4

2. Anderson, J. R. (1996). ACT: A simple theory of complex cognition. American Psychologist, 51(4), 355-365. http://dx.doi.org/10.1037/0003066X.51.4.355

3. Arrand, K. (2014). Peer Tutoring - Journal of Pedagogic Development. Journal of Pedagogic Development, 4(1), 47-61. Retrieved from https://www.beds.ac.uk/jpd/volume-4-issue-1/peertutoring/

4. Bekhet A. and Zauszniewski, J. (2012). Methodological Triangulation: An Approach to 
Understanding Data. Nurse Researcher, 20(2), $40-$ 43. doi: $10.7748 / n r 2012.11 .20 .2 .40 . c 9442$

5. Bell, L., \& Carter, E. (2013). Peer-Mediated Support Strategies. Tennessee Department of Education. Retrieved from https://vkc.mc.vanderbilt.edu/assets/files/resources/ psiPeermedstrategies.pdf

6. Blueprints for Healthy Youth Development. (2019). Peer Assisted Learning Strategies. Retrieved from https://www.blueprintsprograms.org/programs/peer -assisted-learning-strategies/

7. Bone, J., \& Edwards, S. (2015). Connecting in rhizomic spaces: Peer-assisted learning (PAL) and e-learning in teacher education. Australian Journal of Adult Learning, 55(1), 54-74.

8. Carr, S., Brand, G., Wei, L., Wright, H., Nicol, P., Metcalfe, H., . . . Foley, L. (2016). "Helping someone with a skill sharpens it in your own mind": a mixed method study exploring health professions students experiences of Peer Assisted Learning (PAL). BMC Medical Education, 16(48), 1-10. https://doi.org/10.1186/s12909-016-0566-8

9. Center for Research Teaching and Learning (CLRT).(2016). Enhancing Student Learning: Seven Principles for Good Practice. Retrieved from http://www.crlt.umich.edu/gsis/p4_6

10. Cole, J., Ruble, M., Donnelly, J., \& Groves, B. (2018). Peer-assisted Learning: Clinical Skills Training for Pharmacy Students. American Journal of Pharmaceutical Education, 82(6), 644-648.

11. Crawford, D., \& Cannon, E. (2018). Peer learning across the curriculum. Nurse Education Today, 65, 239-241. https://doi.org/10.1016/j.nedt.2018.03.020

12. Drew, S., Phelan, L., Lindsay, K., Carbone, A., Ross, B., Wood, K., . . . Cottman, C. (2017). Formative observation of teaching: focusing peer assistance on teachers' developmental goals. Assessment and Evaluation in Higher Education, 42(6), 914-929.

13. Dunlosky, J., Rawson, K., Marsh, E., Nathan, M., \& Willingham, D. (2013). Improving Students' Learning With Effective Learning Techniques: Promising Directions From Cognitive and Educational Psychology. Psychological Science in the Public Interest, 14(1), 4-58. https://doi.org/10.1177/1529100612453266

14. Dvorak, J., \& Tucker, K. (2017). The Case for Intentionally Interwoven Peer Learning Supports in Gateway-Course Improvement Efforts. New Directions for Higher Education, 2017(180), 43-52. https://doi.org/10.1002/he.20260

15. Glynn, L., MacFarlane, A., Kelly, M., Cantillon, P., \& Murphy, A. (2006). Helping each other to learna process evaluation of peer assisted learning. BMC medical education, 6, 18. https://doi.org/10.1186/1472-6920-6-18

16. Han E-R, Chung E-K, Nam K-I (2015) PeerAssisted Learning in a Gross Anatomy Dissection
Course. PLoS ONE 10(11): e0142988. https://doi.org/10.1371/journal.pone.0142988

17. Hapsari, T., Darhim, \& Dahlan, J. (2018). Understanding and responding the students in learning mathematics through the differentiated instruction. Journal of Physics: Conference Series, 1013, 012136. doi :10.1088/1742$6596 / 1013 / 1 / 012136$

18. Hayes, J. (2017). Employee Retention in the Canadian Gaming/Casino Industry: A Study of the Effects of Customer Service Aptitude, and Essential Skills Math on Short Term Employee Retention (dissertation). College of Education of TUI University.

https://pqdtopen.proquest.com/pubnum/10266990.h tml

19. Mohd Fadzil, Hidayah \& Mohd Saat, Rohaida. (2014). Exploring the influencing factors in students' acquisition of manipulative skills during transition from primary to secondary school. AsiaPacific Forum on Science Learning and Teaching. 15(2). Retrieved from https://eric.ed.gov/?id=EJ1053329

20. Illeris, K. (2018). An overview of the history of learning theory. European Journal of Education, 53(1), 86-101. https://doi.org/10.1111/ejed.12265

21. Institute of Education Sciences. (2013). WWC Intervention Reports:Peer-Assisted Learning Strategies. U.S. Department of Education. Retrieved from https://ies.ed.gov/ncee/wwc/Docs/InterventionRepo $r t s / w w c \_p a l s \_012913 . p d f$

22. Koch, A. (2017). Improving Teaching, Learning, Equity, and Success In Gateway Courses. Retrieved from Wiley Online Library. https://static1.squarespace.com/static/59b0c486d2b 857fc86d09aee/t/5a4ce4450d929722a0edd840/151 4988668839/HE_180.pdf

23. Kodabux, A., Kumar, B., \& Hoolash, A. (2015). Peer learning strategies: Acknowledging lecturers' concerns of the Student Learning Assistant scheme on a new higher education campus. Journal of Peer Learning, 8(1), 59-84. Retrieved from http://ro.uow.edu.au/ajpl/vol8/iss1/7

24. Lang, C., Craig, A., \& Casey, G. (2017). A pedagogy for outreach activities in ICT: Promoting peer to peer learning, creativity and experimentation. British Journal of Educational Technology, 48(6), 14911501. https://doi.org/10.1111/bjet.12501

25. Morice, J., Michinov, N., Delaval, M., Sideridou, A., \& Ferrières, V. $(2015,12$ 1). Comparing the effectiveness of peer instruction to individual learning during a chromatography course. Journal of Computer Assisted Learning, 31(6), 722-733. https://doi.org/10.1111/jcal.12116

26. Mustafa, G. (2017, 9 27). Learning with Each Other: Peer Learning as an Academic Culture among Graduate Students in Education. American 
Journal of Educational Research, 5(9), 944-951. doi: 10.12691/education-5-9-3

27. National Research Council. 2000. How People Learn: Brain, Mind, Experience, and School: Expanded Edition. Washington, DC: The National Academies Press. Retrieved from https://www.desu.edu/sites/flagship/files/document/ 16/how_people_learn_book.pdf

28. Patterson, P. and Lawton, M. (2009). Rubric for Research (Reported in the Traditional Format) Wesley College Department of Education. Wesley College, Delaware, U.S. Retrieved from https://wesley.edu/wp-

content/uploads/2015/07/Research_rubric_2009_. $p d f$

29. Regelski, R. (2016). The Effectiveness of PeerAssisted Learning Strategies on Reading Comprehension For Students With Autism Spectrum Disorder I I(dissertation). University of Pittsburg. Retrieved from http://dscholarship.pitt.edu/29102/

30. Reinholz, D. (2015). The assessment cycle: a model for learning through peer assessment. Assessment \& Evaluation in Higher Education, 41(2), 301-315. doi: 10.1080/02602938.2015.1008982

31. Topping, K., Buchs, C., Duran, D., \& Van Keer, H. (2017). Effective peer learning: From principles to practical implementation. United Kingdom: Taylor \& Francis. https://doi.org/10.4324/9781315695471

32. Ullah, I. \& Tabassum, R. \& Kaleem, M.. (2018). Effects of Peer Tutoring on the Academic Achievement of Students in the Subject of Biology at Secondary Level. Education Sciences. 8(3). 112. https://doi.org/10.3390/educsci8030112

33. vaks. (2019). What is peer learning and why is it important?. Retrieved from https://vaks.co.uk/inspire/peer-learning-important/

34. Wexler, J., Reed, D., Pyle, N., Mitchell, M., \& Barton, E. (2015). A Synthesis of Peer-Mediated Academic Interventions for Secondary Struggling Learners. Journal of Learning Disabilities, 48(5), 451-470.

https://doi.org/10.1177/0022219413504997 